\title{
BlueTApp-Um Aplicativo Móvel para Registro da Frequência Acadêmica através da Tecnologia Bluetooth
}

\author{
Fernando Weber Albiero ${ }^{1}$, João Carlos Damasceno de Lima ${ }^{1}$, Fábio Weber \\ Albiero $^{2}$ \\ ${ }^{1}$ Universidade Federal de Santa Maria (UFSM) \\ Santa Maria - RS - Brasil \\ ${ }^{2}$ Instituto Federal Farroupilha - Campus Santo Ângelo \\ Santo Ângelo - RS - Brasil \\ \{albiero, caio\}@inf.ufsm.br, fabio.albiero@iffarroupilha.edu.br
}

\begin{abstract}
This paper shows an application on mobile devices, the BlueTApp. The BlueTApp was developed for the Android platform and aims, through using Bluetooth technology, to automate the academic frequency record process at educational institutions.
\end{abstract}

Resumo. Este artigo apresenta um aplicativo (app) para dispositivos móveis, o BlueTApp. O BlueTApp foi desenvolvido para a plataforma Android e visa, através do uso da tecnologia Bluetooth, automatizar o processo de registro da frequência acadêmica nas instituições de ensino.

\section{Introdução}

É sabido que a frequência acadêmica em cursos presenciais, em qualquer nível de ensino, é obrigatória e de suma importância para o processo de ensino-aprendizagem.De acordo com a Lei no 9.394 [Brasil 1996], os alunos matriculados em uma disciplina presencial devem possuir frequência mínima para a aprovação de $75 \%$ sobre o total de aulas ministradas e demais atividades acadêmicas.

Na maioria das instituições de ensino, o registro da frequência ainda é realizado de forma tradicional, através do papel e da caneta, o que demanda tempo e tem impacto direto no planejamento institucional. Em alguns casos, um período de tempo considerável da aula é gasto nesse processo, tempo este que poderia ser empregado no processo de ensino-aprendizagem dos alunos. Algumas vezes, visando otimizar a aula, alguns professores até acabam não realizando o controle da frequência, um item importantee obrigatório em uma disciplina presencial. Tal processo poderia ser feito de forma automática e transparente, tanto para os alunos quanto para os professores, através de um sistema ubíquo no qual a frequência seria automaticamente apurada por meio da detecção da presença do aluno e do professor em uma sala de aula, em um determinado horário [Weiser 1991].

Neste contexto, este artigo apresenta um aplicativo móvel, chamado de BlueTApp ${ }^{1}$, para a plataforma Android que, através do uso da tecnologia Bluetooth, automatiza o processo de registro da frequência acadêmica nas instituições de ensino. $\mathrm{O}$

\footnotetext{
${ }^{1}$ BLUETAPP. Patente: Programa de Computador. Número do registro: 512016000682-0, data de registro: 05/07/2016, título: "BLUETAPP", Instituição de registro: INPI - Instituto Nacional da Propriedade Industrial, Depositante(s): Fernando Weber Albiero; João Carlos Damasceno Lima; Fábio Weber Albiero; Universidade Federal de Santa Maria.
} 
aplicativo é responsável por todo o gerenciamento da atividade de chamada, diminuindo assim o número de intervenções por parte do professor.

Este artigo está dividido da seguinte forma: a Seção 2 apresenta os trabalhos correlatos, enquanto que a Seção 3 apresenta o aplicativo BlueTApp, tendo esta a versão do aluno (Subseção 3.1.) e a do professor (Subseção 3.2.). A Seção 4 trata da persistência de dados, fazendo referência ao banco de dados do aplicativo. Por fim, a Seção 5 apresenta os testes e as validações; e a Seção 6, as considerações finais do presente trabalho.

\section{Trabalhos Correlatos}

No mercado atual, as opções para a automação do processo de frequência são limitadas, porém com a evolução da computação móvel e o surgimento de novas tecnologias de comunicação a curta distância, como o Bluetooth, a possibilidade de expandir esse número de opções vem se tornando cada vez maior.

O primeiro exemplo de trabalho correlato foi desenvolvido por alunos da Universidade Católica de Minas, em parceria com a Universidade Centro Leste. Eles desenvolveram um sistema ubíquo para o registro automático da presença acadêmica de alunos [Chamon 2014]. Diferentemente do aplicativo apresentado neste artigo, o sistema desenvolvido pelos alunosda Universidade Católica de Minas funciona através do uso de cartão eletrônico, integrado com um microchip de radiofrequência que é alimentado por uma bateria e busca por uma rede sem fio. Uma vez descoberta a rede, o microchip envia informações para a rede, identificando e localizando o aluno que precisa permanecer, no mínimo, quinze minutos ao alcance da mesma para ter sua presença registrada.

Outro exemplo de trabalho correlato é o IPresence, desenvolvido por um aluno da Universidade Federal do Rio Grande do Sul - UFRGS [Heck 2013]. O IPresence consiste da integração de três subsistemas: a Sala de Aula Virtual (SAV), o WebService e o aplicativo móvel. O SAV é uma plataforma da UFRGS que tem como objetivo facilitar a comunicação e a troca de conteúdo entre alunos e professores. Dentre as principais funções do SAV destacam-se: permitir a troca de mensagens eletrônicas entre alunos e professores, permitir que os professores realizem a chamada diretamente no sistema (é necessário que os professores estejam conectados à rede), permitir que os professores atribuam notas a trabalhos e avaliações; e permitir que os alunos visualizem suas faltas e notas. Por sua vez, oWeb-Service localiza-se no Centro de Processamento de Dados - CPD da instituição e atua como ponte entre o banco de dados do SAV e o aplicativo móvel. É através do Web-Service que o aplicativo móvel se comunica, visando obter as informações necessárias para atualizar o SAV. O IPresencepode ser executado apenas na plataforma iOS.

Por fim, destaca-se um protótipo de hardware para controle da frequência acadêmica, desenvolvido na Universidade Regional de Blumenau [da Silva 2002]. Tal sistema é composto por um kit de hardware, o qual faz uso de um módulo programável RCM2200 e uma placa para o protótipo. Assim como em [Chamon 2014], este sistema é baseado na leitura de cartões eletrônicos, de alunos e professores, armazenando-os na memória, juntamente com o seu horário de leitura. Ao passar o seu cartão no sistema, o professor ativa a recepção dos cartões dos alunos, iniciando assim a chamada. A partir desse momento, todos os códigos dos cartões lidos são armazenados, até que o professor 
VI Congresso Brasileiro de Informática na Educação (CBIE 2017)

Anais dos Workshops do VI Congresso Brasileiro de Informática na Educação (WCBIE 2017)

desative a recepção dos cartões dos alunos, ou seja, encerre a chamada, passando novamente o cartão. Encerrada a chamada, o protótipo deve montar o corpo de um email, estabelecendo aqui uma conexão com um aplicativo servidor para buscar as seguintes informações no banco de dados: nome e e-mail do professor, nomes dos alunos, disciplina e curso. Ao final deste processo, um e-mail contendo todas essas informações é enviado ao endereço eletrônico do professor.

\section{BlueTApp}

O BlueTApp visa automatizar e agilizar o processo de registro da frequência acadêmica nas instituições de ensino. Esse aplicativo foi desenvolvido em linguagem de programação Java, para a plataforma Android. A ideia central do aplicativo é capturar os sinas Bluetooth dos dispositivos móveis (smartphones) dos alunos e através das informações obtidas a partir desses sinais verificar a presença ou ausência dos mesmos em sala de aula. Para tornar isso possível, o aplicativo foi desenvolvido em duas versões: uma versão para o aluno (Subseção 3.1.) e outra para o professor (Subseção 3.2.).

\subsection{BlueTApp Aluno}

A versão do aluno, chamada de BlueTApp Aluno, é muito simples e tem como objetivo principal padronizar o nome dos dispositivos móveis dos alunos. Através dessa padronização, o dispositivo móvel do professor poderá reconhecer e diferenciar cada dispositivo móvel através da captura do sinal Bluetooth. A Figura 1 apresenta a tela inicial do BlueTApp Aluno.

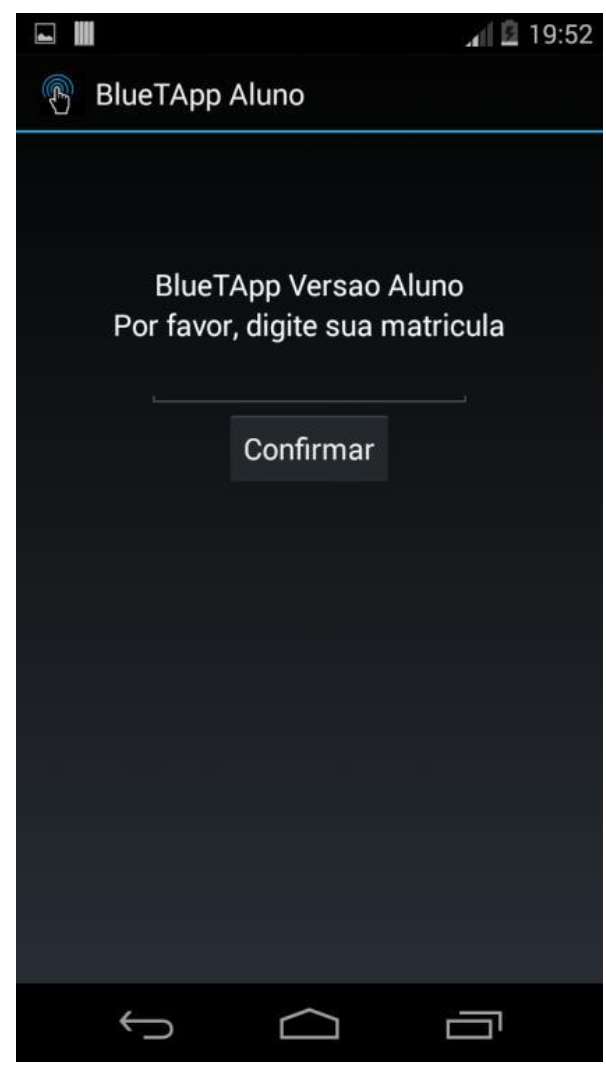

Figura1. Tela inicial do BlueTApp Aluno. 
VI Congresso Brasileiro de Informática na Educação (CBIE 2017)

Anais dos Workshops do VI Congresso Brasileiro de Informática na Educação (WCBIE 2017)

O BlueTApp Aluno funciona da seguinte forma: após o preenchimento do campo "Matrícula", que tem valor numérico e é de preenchimento obrigatório (não pode estar vazio - e caso isso ocorra, um alerta será exibido) e a confirmação da operação através de um clique no botão "Confirmar", o aplicativo solicita ao aluno a permissão para utilizar o adaptador Bluetooth do aparelho, tornando-o visível para outros dispositivos. Sendo aceita a solicitação, o aplicativo modifica o seu estado para "ligado" e altera o nome do dispositivo para a matrícula informada no campo de texto. Se o adaptador já estiver ligado, o aplicativo simplesmente modifica o nome do dispositivo para a matrícula informada pelo aluno.Após executar essa operação, o aplicativo torna 0 dispositivo visível para os outros dispositivos móveis e uma mensagem é exibida para o aluno informando que seu aparelho está pronto para a chamada por Bluetooth.

O tempo de visibilidade do dispositivo móvel varia de acordo com as versões da plataforma Android. Conforme a documentação do Google [Android Developers 2017], empresa detentora dos direitos da plataforma Android, as versões mais antigas da plataforma (2.*) têm um tempo máximo de 300 segundos. Já a partir das versões $3 .^{*}$, o limite de tempo foi incrementado, podendo chegar a 3600 segundos. O BlueTApp Aluno utiliza sempre o tempo máximo de visibilidade permitido, em função da versão da plataforma Android.

Destaca-se que não há necessidadedo uso da versão BlueTApp Aluno para o registro da frequência.O BlueTApp Aluno é simplesmente uma ferramenta facilitadora para ativar o adaptador Bluetooth e alterar o nome do dispositivo móvel para a matrícula do aluno. Portanto, tais passos ainda podem ser executados de forma manual pelo aluno (Menu $\rightarrow$ Configurações $\rightarrow$ Conexões sem fio e rede $\rightarrow$ Configurações Bluetooth $\rightarrow$ Ativar) para o reconhecimento do aparelho pela versão BlueTApp Professor.

\subsection{BlueTApp Professor}

A versão do professor, chamada de BlueTApp Professor, é responsável pelo processo de registro acadêmico de forma automática e transparente. Antes da execução da aplicação, o professor deve acessar o Portal do Professor da UFSM e realizar o download dos arquivos .csv referentes as turmas as quais ele irá realizar a chamada. Os dados contidos nos arquivos .csv serão importados e armazenados pelo aplicativo no momento em que o professor tentar inserir uma nova turma. $\mathrm{O}$ arquivo .csv possui o seguinte formato: nome, matrícula, data de inclusão do aluno na turma, curso e e-mail do aluno. Caso o professor não tenha acesso ao Portal do Professor da UFSM ou não seja professor desta instituição, basta criar um arquivo neste formato e importá-lo para o dispositivo móvel (mais precisamente no diretório do aplicativo). A Figura 2 apresenta um trecho de um arquivo .csv importado do Portal do Professor da UFSM.

\footnotetext{
nome,matrícula,data de inclusão na turma, curso,e-mail

ALAN PERALTA DUTRA,201222150,28/07/2014,Bacharelado em Sistemas de Informação,adutra@inf.ufsm.br

ANDRE LUIS GIACOMINI BRENDLER,201240234,28/07/2014,Bacharelado em Sistemas de Informação,andre_brendler@hotmail.com CRISTOFER ROVIAN CLARO PEDROSO,2921130,25/08/2014,Curso de Engenharia de Computação,crisrcp@gmail.com

EMIR NATAL BRITO DE CAMPOS JUNIOR,2920918,28/07/2014,Bacharelado em Sistemas de Informação,emircampos@gmail.com

FERNANDO QUATRIN CAMPAGNOLO,201120061,11/08/2014,Bacharelado em Sistemas de Informação,fcampagnolo@inf.ufsm.br

HERSON FLACH NADALON,201040150,28/07/2014,Bacharelado em Sistemas de Informação,hnadalon@inf.ufsm.br

JUNIOR DE SOUZA,201020579,22/08/2014,Curso de Engenharia de Computação,junior.souza2102@gmail.com

MARCO ANTONIO DALCIN,201020318,25/08/2014,Curso de Engenharia de Computação,marco_dalcin@hotmail.com
}

Figura2. Trecho de um arquivo no formato .csv importado do Portal do Professor da UFSM. 
VI Congresso Brasileiro de Informática na Educação (CBIE 2017)

Anais dos Workshops do VI Congresso Brasileiro de Informática na Educação (WCBIE 2017)

Ao executar o aplicativo BlueTApp Professor pela primeira vez, é criado um diretório dentro da pasta nativa de diretórios do Android, com o nome BlueTApp, aonde posteriormente serão armazenados os arquivos referentes ao funcionamento da mesma. Ainda na primeira execução, o professor fica limitado a inserir uma nova turma, como é mostrado na Figura 3. A Figura 4 mostra a tela do aplicativo BlueTApp Professor para a criação de uma nova turma.

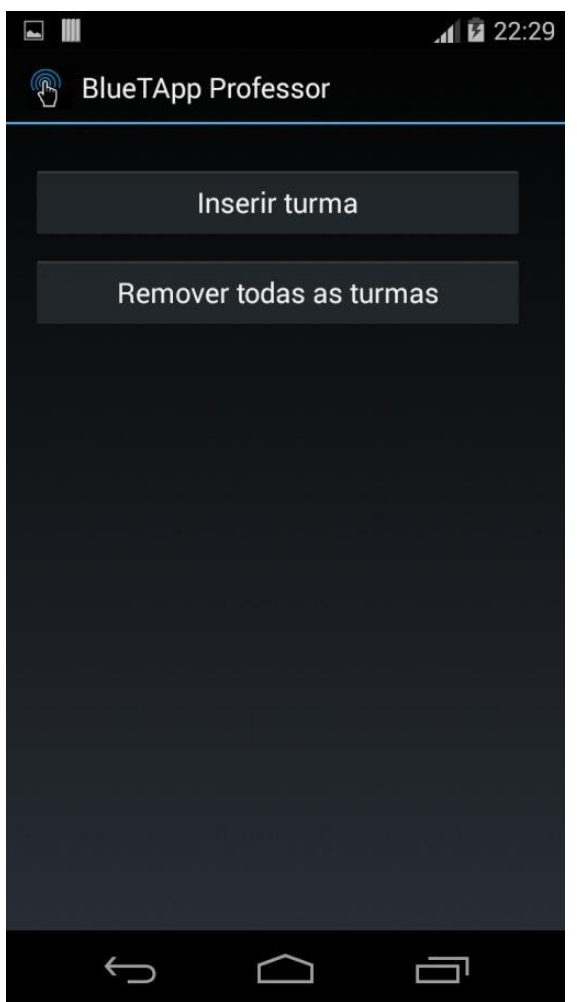

Figura 3. Tela inicial do BlueTApp Professor, solicitando ao professor a inserção uma nova turma.

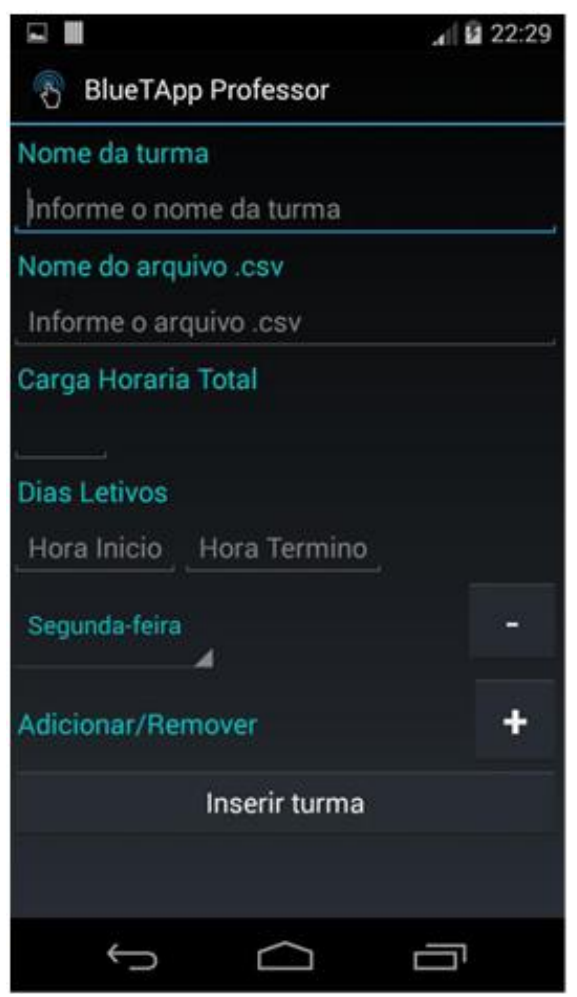

Figura 4. Tela do BlueTApp Professor para a criação de uma nova turma.

Após preencher os campos do formulário e clicar no botão "Inserir turma", a turma é criada e passa a ser exibida na tela inicial da aplicação, como é mostrado na Figura 5. Uma mensagem também é exibida ao professor confirmando que a operação foi realizada com sucesso.

Ao executar a aplicação, as turmas anteriormente adicionadas são listadas e o professor não fica mais limitado a inserir novas turmas. Ao efetuar um clique curto sobre alguma das turmas existentes na lista, as informações, que foram importadas do arquivo .csv, sobre cada aluno da turma são exibidas, como mostrado na Figura 6 . Além disso, o número e a percentagem de faltas de cada aluno também são exibidos. A percentagem de faltas é calculada através da seguinte fórmula:

$$
\text { Pfaltas }=\frac{N \text { faltas } \times 100}{\text { Chrt }}
$$

onde:

- Pfaltas é a percentagem de faltas do aluno;

- Nfaltas é o número de faltas do aluno; e

- Chrt é a carga horária total da disciplina. 
VI Congresso Brasileiro de Informática na Educação (CBIE 2017)

Anais dos Workshops do VI Congresso Brasileiro de Informática na Educação (WCBIE 2017)

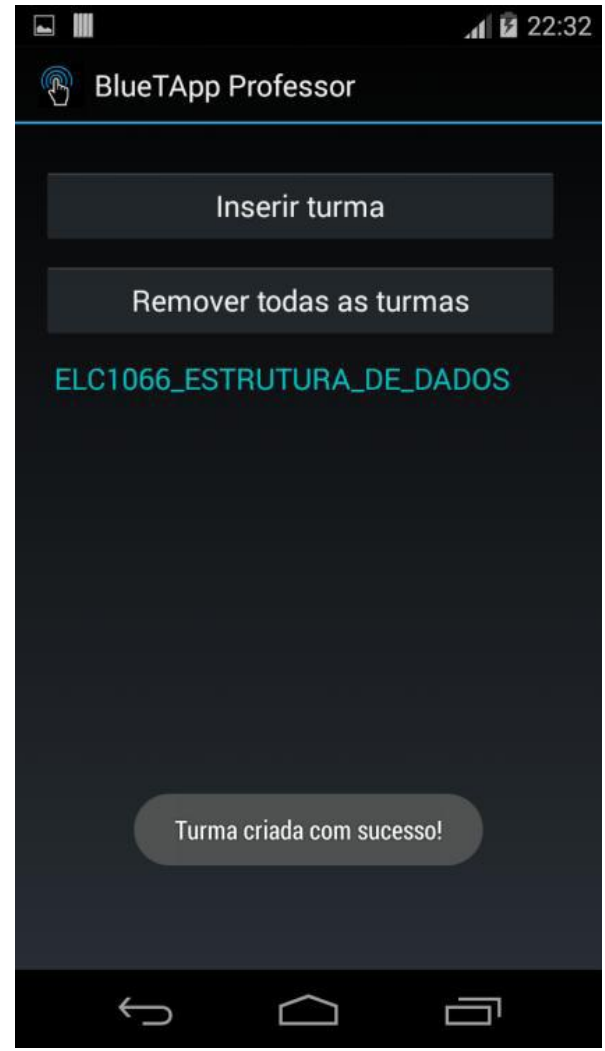

Figura 5. Tela do BlueTApp Professor após a criação de uma turma.

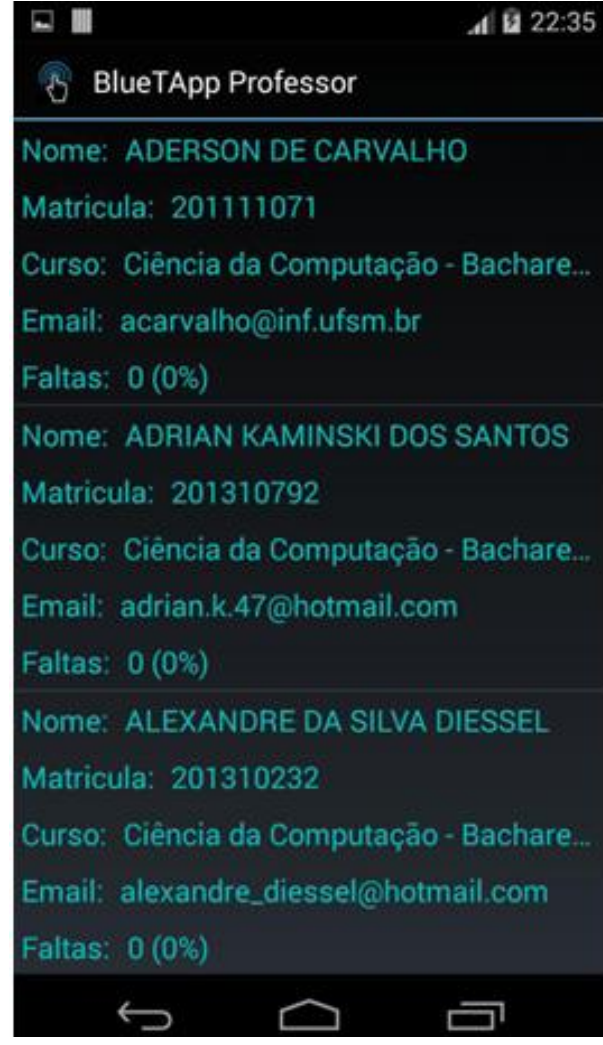

Figura 6. Tela do BlueTApp Professor exibida após um clique curto em alguma turma.

Dentre as principais ações, o aplicativo BlueTApp Professor permite ao docente: inserir e remover turmas; inserir e remover alunos; realizar o controle da frequência via Bluetooth ou de forma manual; exportar os dados no formato .csv, etc. As Figuras7 e 8 apresentam, respectivamente, o diagrama de casos de uso e o diagrama de sequência do BlueTApp Professor.

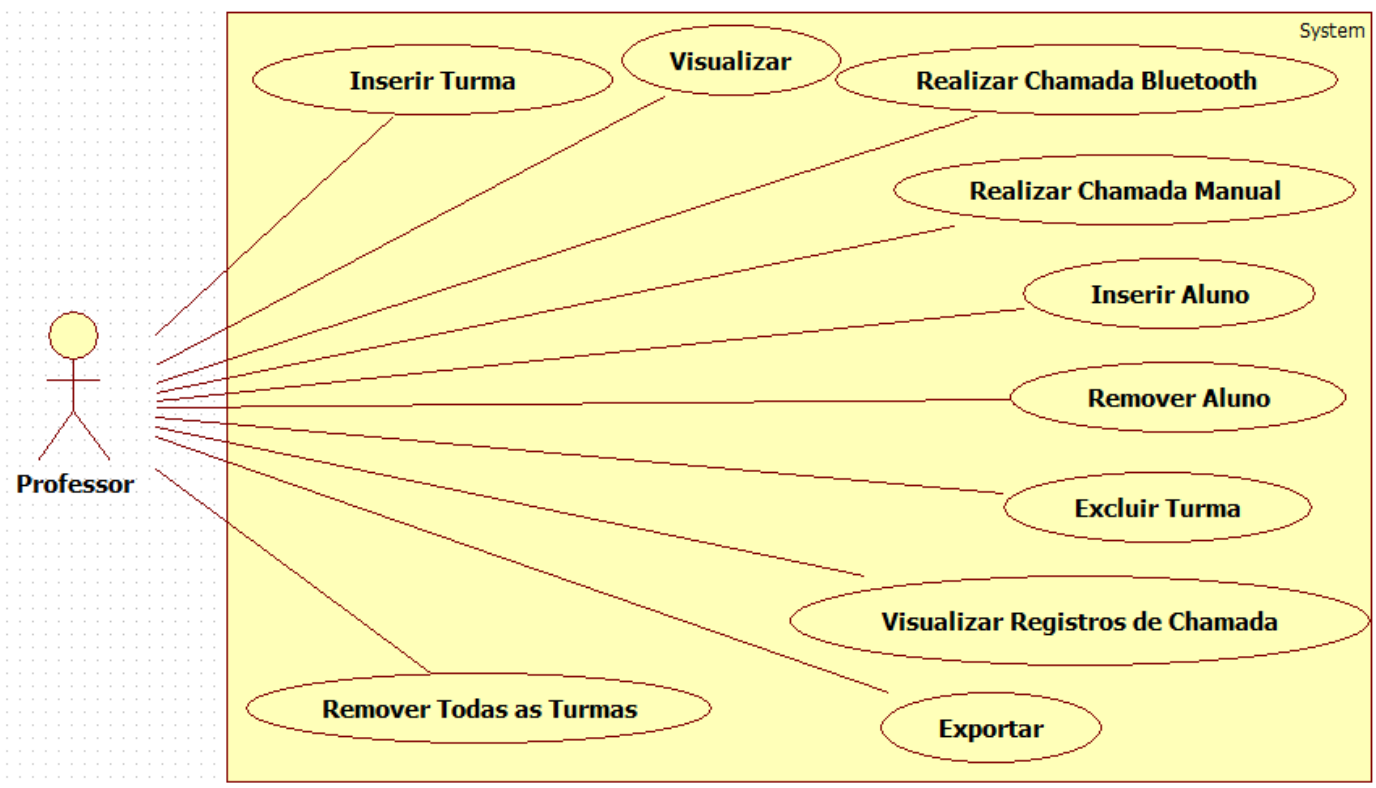

Figura 7. Diagrama de casos de uso do BlueTApp Professor. 
VI Congresso Brasileiro de Informática na Educação (CBIE 2017)

Anais dos Workshops do VI Congresso Brasileiro de Informática na Educação (WCBIE 2017)

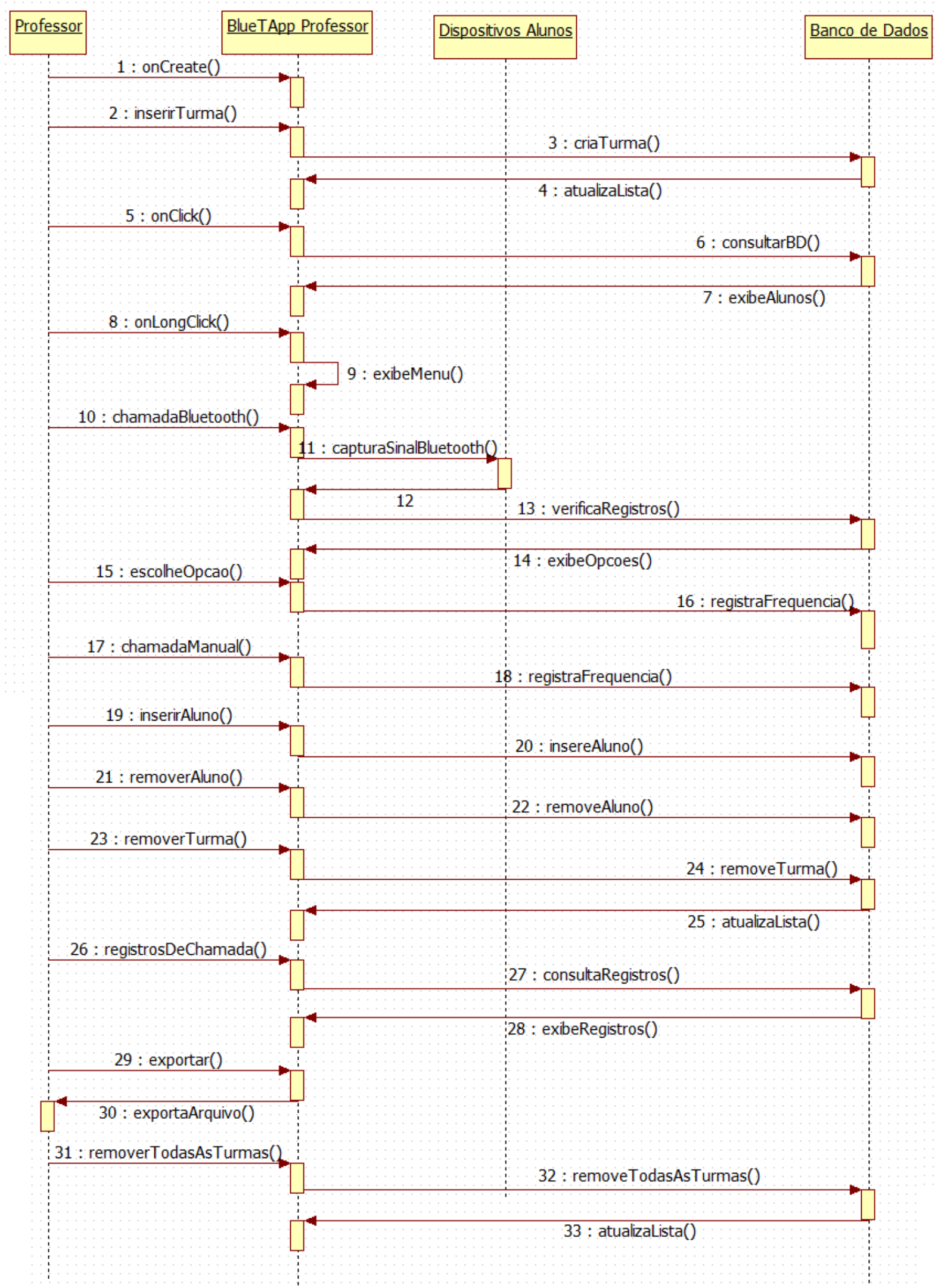

Figura 8. Diagrama de sequência do BlueTApp Professor. 
VI Congresso Brasileiro de Informática na Educação (CBIE 2017)

Anais dos Workshops do VI Congresso Brasileiro de Informática na Educação (WCBIE 2017)

$\mathrm{O}$ arquivo gerado a partir da exportação leva o nome da turma seguido da palavra "Frequencias" e é armazenado no diretório BlueTApp, criado pelo próprio aplicativo. Um trecho de um arquivo exportado pelo BlueTApp Professor é apresentado na Figura 9. Como mostrado nesta figura é possível notar que o arquivo é composto de duas colunas, sendo uma referente à matrícula dos alunos e outra ao vetor de frequências dos mesmos.

matrícula,frequência

201111071,АРРААРААРАРААРРРАРРАРААРРАРАРААРРАРАРААРРРРРААРРААРААРАРААРРРАРРАРААРРАРАРААРРАРА 201310792,РPААРААРРРРРРРАРААРРАРААРРРАААРАРАРААРРРАРАРРРРРАРААРРРРАРААРРАРААРРРАААРАРАРААРАА 201310232,ААРРРРААРАРААРРРАРААРРРАРААРРРАРААРРРАРААРРРАРАРРААРААРАРААРРРАРРАРААРРАРАРААРРАРА

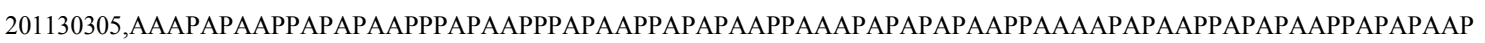

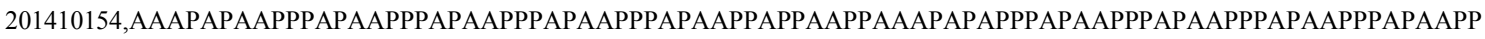

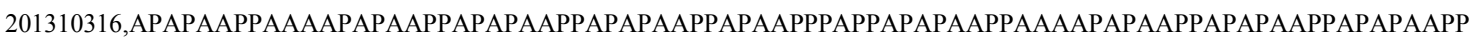
201212732,АAАРАРААРРРАРААРРРАРАРАРААРРАРРААРАРААРРРАРРРАРАРААРРААААРАРААРРАРАРААРРАРАРААРРА

Figura 9. Formato do arquivo .csv exportado pelo BlueTApp Professor.

\section{Persistência de Dados}

A persistência de dados na aplicação BlueTAppfoi desenvolvida utilizando o banco de dados nativo da plataforma Android, o SQLite. Os dados referentes à aplicação foram armazenados em dois tipos de tabelas: turma e registro de chamada.

Basicamente, cada turma é uma tabela no banco de dados. A tabela leva o nome da turma e é criada no momento em que o professor adiciona uma nova turma. Cada linha da tabela do tipo turma armazena um aluno daquela turma. As tabelas desse tipo possuem as colunas: ID, nome, matrícula, frequência, Bluetooth Address, curso e email; conforme pode ser visto na Tabela 1 . A coluna ID é preenchida automaticamente pelo banco de dados de forma auto incremental a partir de cada aluno importado do arquivo .csv. As colunas nome, matrícula, curso e e-mail são preenchidas a partir das informações importadas do arquivo .csv.

Tabela 1. Exemplo de tabela do tipo turma.

\begin{tabular}{|c|c|c|c|c|c|c|}
\hline ID & nome & matrícula & frequência & Bluetooth Address & curso & e-mail \\
\hline 1 & Fulano & 123456 & PPPPAA & 0C:DF:A4:C0:9E:ED & $\begin{array}{c}\text { Ciência da } \\
\text { Computação }\end{array}$ & fulano@email.com \\
\hline
\end{tabular}

A coluna frequência permanece vazia até o momento em que uma chamada é realizada. Essa coluna é representada por umaString aonde cada caractere equivale a uma hora de aula e é incrementada cada vez que uma chamada é realizada. A letra "P" representa uma presença, enquanto a letra "A" representa uma ausência. O tamanho do incremento da String é determinado pelo professor no momento anterior a realização da chamada; em outras palavras, quando ele indica a carga horária da disciplina.

Por sua vez, a coluna Bluetooth Address só é preenchida no momento em que uma chamada por Bluetooth é efetuada. Ao encontrar os sinais Bluetooth dos dispositivos móveis dos alunos, o aplicativo do professor compara o nome do dispositivo encontrado, que no caso é a matrícula do aluno, com a matrícula presente no banco de dados. Caso as duas sejam iguais, a coluna Bluetooth Address, que está associada ao aluno, é preenchida com esse endereço. Assim, nas próximas vezes que a chamada por Bluetooth for realizada, o aluno só obterá a presença caso o Bluetooth Address encontrado seja o mesmo ao endereço anteriormente associado a ele. Isso evita 
VI Congresso Brasileiro de Informática na Educação (CBIE 2017)

Anais dos Workshops do VI Congresso Brasileiro de Informática na Educação (WCBIE 2017)

que um aluno se passe por outro, através da troca do nome do dispositivo para a matrícula de outro aluno.

Já uma tabela do tipo registro de chamada (veja a Tabela 2) é criada no momento em que uma chamada é realizada. Ela tem como nome, o nome da turma seguido da palavra "Registro". Tabelas do tipo registro de chamada possuem as seguintes colunas: ID, data, presenças, ementa, posição inicial e posição final. A coluna data é referente à data em que a chamada foi realizada, a coluna presenças indica o número de alunos que estavam presentes quando esta chamada foi realizada e a coluna ementa é referente ao assunto da aula, indicado pelo professor no momento anterior à realização da chamada. As colunas posição inicial e final indicam a posição da chamada realizada no vetor de frequências.

Tabela 2. Exemplo de tabela do tipo registro de chamada.

\begin{tabular}{|c|c|c|c|c|c|}
\hline ID & data & presenças & ementa & posição inicial & posição final \\
\hline 1 & $15 / 11 / 14$ & 28 & Orientação a Objetos - Classes & 2 & 3 \\
\hline
\end{tabular}

Através da quantidade de registros existentes nas tabelas do tipo registro de chamada é possível verificar a quantidade de chamadas realizadas pelo professor em cada disciplina que o mesmo leciona. Os registros das tabelas do tipo registro de chamada também são utilizados para verificar se uma chamada já foi realizada naquele dia, oferecendo ao professor as opções de realizar uma nova chamada ou sobrescrever a chamada anterior (já existente).

Ao escolher a opção "Nova Chamada", um novo registro é adicionado à tabela de registro de chamadas e o vetor de frequências é atualizado com as novas informações. Se a opção escolhida for "Sobrescrever a Anterior", a última chamada realizada é editada, assim como o último registro da tabela de registro de chamada, de forma que os caracteres referentes à última chamada no vetor de frequências são atualizados.

Quando o professor realiza mais de uma chamada por aula, espera-se que a carga horária da aula, informada no momento anterior a realização da chamada, seja dividida pelo número de chamadas. Por exemplo, se a aula tem duração de duas horas e o professor deseja realizar duas chamadas nesse período, uma no início da aula e outra no final, a carga horária referente a cada chamada deve ser de uma hora. Dessa forma, ao final do semestre, o tamanho da String de frequências será relativo ao número de horasaula.

\section{Testes e Validação dos Resultados}

O primeiro desafio encontrado foi escolher qual o tipo de comunicação Bluetooth seria mais vantajosa em termos de desempenho e velocidade para conectar o dispositivo móvel do professor aosdispositivos móveis dos alunos. Tal comunicação poderia se dar de duas formas: com o pareamento e a abertura de um canal para a troca de mensagens ou sem o pareamento. Para descobrir qual tipo de comunicação era mais viável, foram realizados testes em um ambiente controlado, com quatro dispositivos móveis, atuando um como o dispositivo móvel do professor e os demais como os dispositivos móveis dos alunos.

O primeiro teste se deu da seguinte forma: após a descoberta dos sinais Bluetooth dos dispositivos que estavam atuando como alunos, o aparelho do professor 
solicitou o pareamento com esses dispositivos. Através deste teste foi possível verificar que o pareamento não pode ser efetuado de forma simultânea com todos os dispositivos ao mesmo tempo, ou seja, o aparelho do professor precisa criar um buffer de pareamento, na ordem cujos sinais foram sendo descobertos e enviar, posteriormente, as solicitações de pareamento uma a uma para os dispositivos móveis. Isso ocorre porque, ao solicitar o pareamento, uma chave única é compartilhada entre os dois dispositivos que estão tentando efetuar a operação. Como a operação de pareamento é bloqueante, se mais algum dispositivo tentar efetuar o pareamento antes do primeiro ter sido completado, a segunda chave é perdida e o segundo procedimento de pareamento não é completado.

O tempo de pareamento com até três dispositivos é apresentado na Figura 10. Os dados apresentados nesta figura foram calculados através da média aritmética dos tempos de pareamento de cinco testes. Através da análise da Figura 10 é possível perceber que, conforme aumenta o número de dispositivos envolvidos no processo, o tempo para a realização da descoberta do sinal e do paramento aumentam de forma linear, se tornando assim algo inviável. Através deste teste foi possível verificar que efetuando o pareamento entre os dispositivos móveis, os objetivos propostos neste trabalho estariam comprometidos. Portanto, visando não comprometer tais objetivos, optou-se pelo não pareamento entre os dispositivos e, consequentemente, pela não troca de mensagens entre os mesmos, embora esta opção seja menos segura do que a outra.

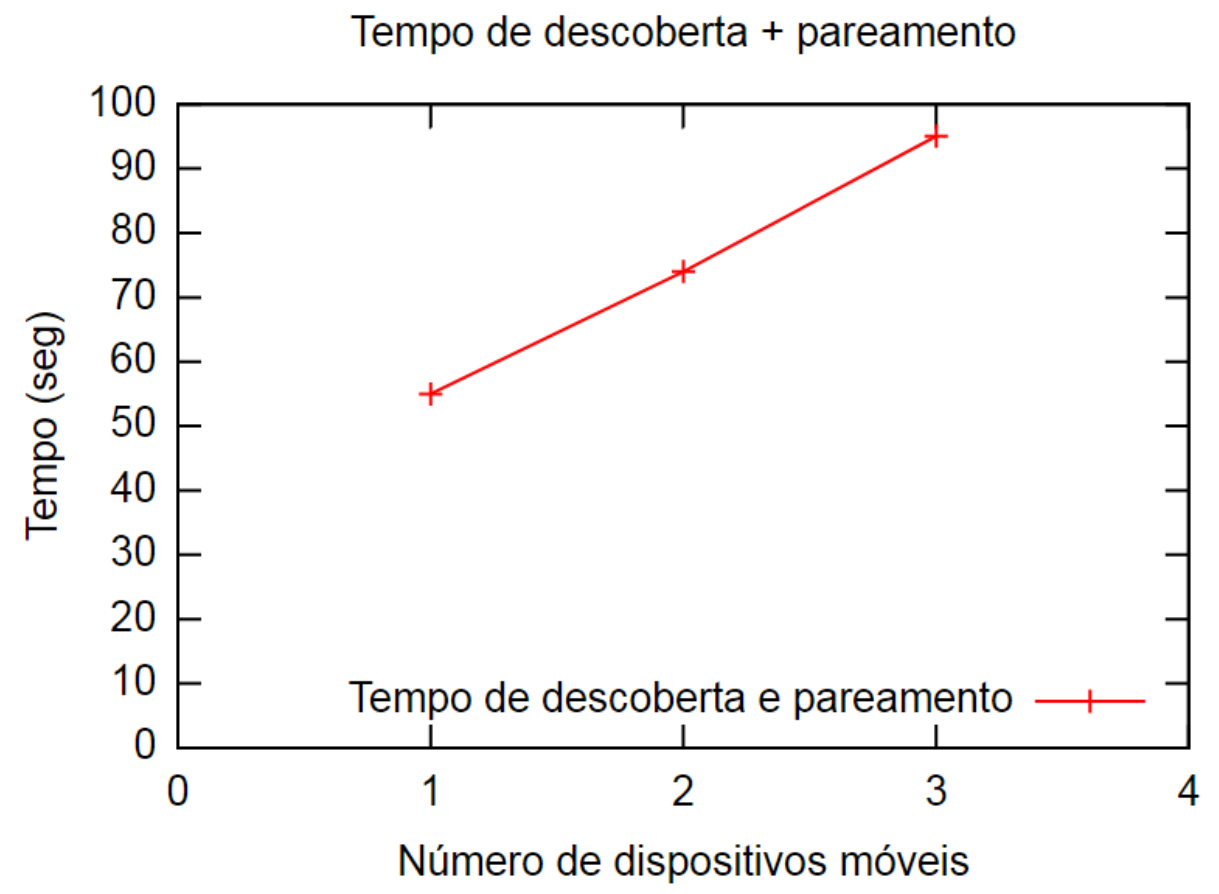

Figura 10. Gráfico com o tempo de descoberta e pareamento de dispositivos móveis.

Após a escolha do tipo de comunicação, um segundo teste foi realizado visando mensurar o tempo de descoberta dos sinais Bluetooth, sem a realização do pareamento. Este teste foi realizado em ambiente controlado e também na sala de aula. Para tornar este teste possível, foi solicitado aos alunos da aula de Fundamentos de Banco de Dados, da Universidade Federal de Santa Maria, que instalassem a versão BlueTApp Aluno em seus dispositivos móveis. Aos alunos que estavam utilizando dispositivos com outras plataformas que não o Android, foi solicitado que efetuassem de maneira 
VI Congresso Brasileiro de Informática na Educação (CBIE 2017)

Anais dos Workshops do VI Congresso Brasileiro de Informática na Educação (WCBIE 2017)

manual os passos realizados pelo aplicativo BlueTApp Aluno. Este teste foi realizado com um total de nove alunos. Sendo assim, ficamos limitados a esta quantidade de dispositivos móveis. Visto que o objetivo era mensurar o tempo de busca dos sinais Bluetooth, conforme a quantidade de dispositivos envolvidos no processo, várias chamadas por Bluetooth tiveram que ser efetuadas. Na primeira chamada, foram utilizados quatro dispositivos. A cada teste, um dispositivo móvel era acrescido, até atingirmos o nosso limite. A Figura 11 mostra o tempo de descoberta dos sinais Bluetooth dos dispositivos móveis dos alunos.

\section{Tempo de descoberta}

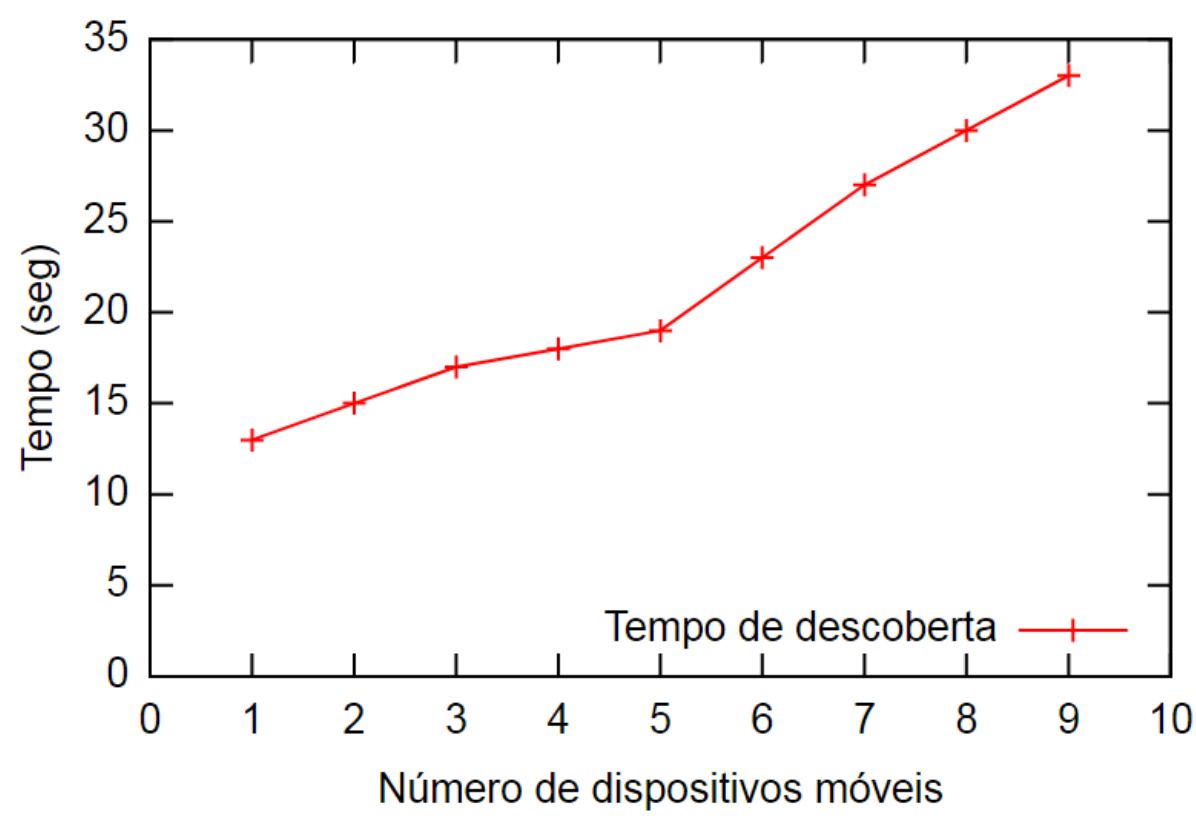

Figura 11. Gráfico com o tempo de descoberta dos dispositivos móveis em um ambiente real.

Este período em sala de aula serviu também para validar a eficiência do aplicativo, que em $100 \%$ dos casos, conseguiu capturar os sinais Bluetooth de todos os aparelhos móveis dos alunos envolvidos no teste, bem como registrar a frequência de forma automática, alcançando assim os objetivos propostos neste trabalho.

\section{Considerações Finais}

Este trabalho apresenta como contribuição um aplicativo móvel para a automação e gerenciamento do registro da frequência acadêmica nas instituições de ensino. $\mathrm{O}$ aplicativo também pode ser usado como ferramenta de consulta para os professores, podendo estes obterem informações dos alunos e das aulas já ministradas.

Como trabalho futuro, espera-se aumentar o número de funcionalidades do aplicativo, iniciando pela execução do mesmo de forma automática. Isso seria possível a partir das informações obtidas no formulário de inserção de uma nova turma (com dias letivos e horários das aulas).Outras possibilidades de melhoria do BlueTApp a serem implementadas são: permitir que os alunos utilizem mais de um dispositivo móvel para participar do processo de registro da frequência acadêmica e expandir a fronteira do aplicativo para os alunos, de tal maneira que possam consultar sua situação de frequência de forma independente do aplicativo BlueTApp Professor. 
VI Congresso Brasileiro de Informática na Educação (CBIE 2017)

Anais dos Workshops do VI Congresso Brasileiro de Informática na Educação (WCBIE 2017)

Como trabalhos futuros, também espera-se disponibilizar este aplicativo para a plataforma iOS, assim como desenvolver mecanismos de segurança, como alguns protocolos, afim de evitar que o aluno possa receber presença sem estar realmentena sala de aula. Além disso, espera-se executar o aplicativo em turmas com mais alunos, visando comprovar sua real eficácia no que tange ao processo de registro da frequência acadêmica.

Por fim, espera-se que num futuro próximo este aplicativo conquiste seu espaço dentro das instituições de ensino, facilitando a tarefa de realização da frequência acadêmica, tanto para os professores quanto para os alunos.

\section{Referências}

Android Developers. "Bluetooth", https://developer.android.com/guide/topics/connectivity/bluetooth.html, Agosto de 2017.

Brasil. (1996) Lei $\mathrm{n}^{0}$ 9.394, de 20 de dezembro de 1996, http://www.planalto.gov.br/ccivil_03/leis/L9394.htm, Agosto de 2017.

Chamon, J. P. M. (2014). "Registro Ubíquo de Controle Acadêmico: Localização em Ambiente Interno Utilizando Ciclo de Trabalho Dinâmico". In XXXIV Congresso da Sociedade Brasileira de Computação.

da Silva, F. L. M. (2002) "Protótipo de um Hardware para Controle de Frequência Acadêmica", $\quad$ http://dsc.inf.furb.br/arquivos/tccs/monografias/20021 fernandoluizmelatidasilvavf.pdf, Agosto de 2017.

Heck, F. S. (2013) "Sistema Móvel de Controle de Presença", https://www.lume.ufrgs.br/bitstream/handle/10183/100288/000931702.pdf?sequence $=1$, Agosto de 2017 .

Weiser, M. (1991) "The Computador for the 21st Century", https://www.lri.fr/ mbl/Stanford/CS477/papers/Weiser-SciAm.pdf, Agosto de 2017. 